\title{
Two Modes of Release Shape the Postsynaptic Response at the Inner Hair Cell Ribbon Synapse
}

\author{
Lisa Grant, Eunyoung Yi, and Elisabeth Glowatzki \\ The Johns Hopkins School of Medicine, Department of Otolaryngology-Head and Neck Surgery, Baltimore, Maryland 21205
}

Cochlear inner hair cells (IHCs) convert sounds into receptor potentials and via their ribbon synapses into firing rates in auditory nerve fibers. Multivesicular release at individual IHC ribbon synapses activates AMPA-mediated EPSCs with widely ranging amplitudes. The underlying mechanisms and specific role for multivesicular release in encoding sound are not well understood. Here we characterize the waveforms of individual EPSCs recorded from afferent boutons contacting IHCs and compare their characteristics in immature rats (postnatal days 8-11) and hearing rats (postnatal days 19-21). Two types of EPSC waveforms were found in every recording: monophasic EPSCs, with sharp rising phases and monoexponential decays, and multiphasic EPSCs, exhibiting inflections on rising and decaying phases. Multiphasic EPSCs exhibited slower rise times and smaller amplitudes than monophasic EPSCs. Both types of EPSCs had comparable charge transfers, suggesting that they were activated by the release of similar numbers of vesicles, which for multiphasic EPSCs occurred in a less coordinated manner. On average, a higher proportion of larger, monophasic EPSCs was found in hearing compared to immature rats. In addition, EPSCs became significantly faster with age. The developmental increase in size and speed could improve auditory signaling acuity. Multiphasic EPSCs persisted in hearing animals, in some fibers constituting half of the EPSCs. The proportion of monophasic versus multiphasic EPSCs varied widely across fibers, resulting in marked heterogeneity of amplitude distributions. We propose that the relative contribution of two modes of multivesicular release, generating monophasic and multiphasic EPSCs, may underlie fundamental characteristics of auditory nerve fibers.

\section{Introduction}

Cochlear inner hair cells (IHCs) convert sound signals into receptor potentials and subsequently, at their afferent synapses with auditory nerve fibers, into firing rates that are relayed to the CNS. Hair cell ribbon synapses, like retinal ribbon synapses, are specialized for fast and continuous glutamate release (Heidelberger et al., 2005; Nouvian et al., 2006). The presynaptic ribbon's role is poorly understood; however, it has been proposed to support the continuous release of vast numbers of vesicles (Parsons and Sterling, 2003; Zenisek, 2008; LoGiudice and Matthews, 2009). The presynaptic machinery at hair cell ribbon synapses appears to operate in a specialized manner. For example, synaptotagmin IV or otoferlin, rather than synaptotagmins I or II, the principal calcium sensors in the CNS have been postulated to act as calcium sensors at the IHC afferent synapse (Safieddine and Wenthold, 1999; Lenzi and von Gersdorff, 2001; Roux et al., 2006; Johnson et al., 2009). Furthermore, several ribbon synapses have been shown to operate by multivesicular release, where multiple vesicles can be released in a coordinated manner to activate individual EPSCs

Received Sept. 4, 2009; revised Jan. 26, 2010; accepted Jan. 28, 2010.

This work was supported by National Institute on Deafness and Other Communication Disorders DC006476 to E.G. We thank Soroush Sadeghi for writing a routine in Matlab to analyze synaptic events, Sean Slee for helpful insights into data analysis, and Eric Young, Brad May, and Paul Fuchs for stimulating discussions and comments on earlier versions of this manuscript. We thank two anonymous reviewers for their thoughtful comments.

Correspondence should be addressed to Elisabeth Glowatzki, The Johns Hopkins School of Medicine, Department of Otolaryngology-Head and Neck Surgery, 720 Rutland Avenue, Ross 824, Baltimore, MD 21205. E-mail: eglowat1@jhmi.edu.

DOI:10.1523/JNEUROSCI.4439-09.2010

Copyright $\odot 2010$ the authors $\quad 0270-6474 / 10 / 304210-11 \$ 15.00 / 0$ of varying amplitudes (Glowatzki and Fuchs, 2002; Singer et al., 2004; Keen and Hudspeth, 2006; Singer and Diamond, 2006; Suryanarayanan and Slaughter, 2006; Neef et al., 2007; Li et al., 2009). Finally, at the IHC afferent synapse in the immature rat cochlea, EPSC amplitudes are independent of presynaptic calcium influx over the physiological range of depolarization (Glowatzki and Fuchs, 2002; Goutman and Glowatzki, 2007).

At rat IHC afferent synapses, multivesicular EPSCs appear with unusual shapes. Some EPSCs exhibiting sharp rise times and monoexponential decays (monophasic) have large amplitudes, suggesting highly synchronous fusion of multiple vesicles. Other EPSCs show inflections during rising and decaying phases (multiphasic), suggestive of a less well coordinated multivesicular release (Glowatzki and Fuchs, 2002). The specific release mechanisms supporting monophasic and multiphasic EPSCs are unknown. At the adult frog hair cell synapse, multiphasic EPSCs constitute $<5 \%$ of EPSCs (Keen and Hudspeth, 2006; Li et al., 2009), whereas at immature rat IHC afferent synapses multiphasic EPSCs amount to 30\% of EPSCs (Glowatzki and Fuchs, 2002). The question arises whether multiphasic EPSCs are a feature of immature IHC synapses, or whether they represent a specific mode of release with functional relevance in the mature cochlea. Here we characterize and compare EPSCs of afferent boutons contacting IHCs in immature [postnatal days 8-11 (P8-11)] and hearing (P19-21 and P60) rat cochleae. In addition to charting developmental changes in synaptic physiology, we assess the contribution of multiphasic EPSCs and determine whether EPSC amplitudes are calcium independent at IHC afferent synapses of hearing rats. We find variability in the ratio of monophasic to 
multiphasic EPSCs across individual IHC ribbon synapses and propose that this may contribute toward setting the diverse firing patterns of auditory nerve fibers.

\section{Materials and Methods}

Whole-cell voltage-clamp recordings were made from afferent fiber terminals innervating IHCs of immature (P8-11, where P0 is the day of birth), and hearing rats (P19-21 and P60) and from IHCs (at P19-21) as described previously for immature rats (Glowatzki and Fuchs, 2002). In accordance with animal protocols approved by the Johns Hopkins University Animal Care and Use Committee, rats (Sprague Dawley; Charles River) were deeply anesthetized by pentobarbital $0.045 \mathrm{mg} \mathrm{g}^{-1}$ i.p. or isoflurane inhalation and decapitated. Cochleae were removed from the temporal bone and placed in standard extracellular solution (see below). The apical coil was excised, stria vascularis and tectorial membrane were removed, and the preparation was secured under a pin fixed to a coverslip. The coverslip was then transferred to the recording chamber, in which the preparation was viewed using a $40 \times$ water-immersion differential interference contrast (DIC) objective (Axioskop FS microscope, Zeiss) with $4 \times$ magnification through a NC70 Newvicon camera (Dage MTI). In the recording chamber, extracellular solution was perfused at a rate of $1.5 \mathrm{ml} \mathrm{min}^{-1}$. Dissections yielded healthy-looking hair cells, with intact hair bundles and slender cell bodies. Preparations were discarded if hair cells became swollen or more transparent. The recording site was restricted to the apical coil and estimated to be in the region in which sound frequencies of $2-5 \mathrm{kHz}$ are represented (Müller, 1991a). Recordings were performed at room temperature $\left(22-25^{\circ} \mathrm{C}\right)$.

Recording pipettes were fabricated from $1 \mathrm{~mm}$ borosilicate glass (WPI). Pipettes were pulled with a multistep horizontal puller (Sutter) and fire polished (10-15 M $\Omega$ for afferent fibers and 5-6 M $\Omega$ for IHCs). Pipettes were coated with Sylgard (Dow Corning). Intracellular solutions for afferent recordings were either of the following (in $\mathrm{mM}$ ): $20 \mathrm{KCl}, 110$ K-methanesulfonate, $5 \mathrm{MgCl}_{2}, 0.1 \mathrm{CaCl}_{2}, 5$ EGTA, 5 HEPES, $5 \mathrm{Na}_{2} \mathrm{ATP}$, $0.3 \mathrm{Na}_{2} \mathrm{GTP}, 5 \mathrm{Na}_{2}$ phosphocreatine, pH $7.2(\mathrm{KOH}), 290 \mathrm{mOsm}$; or 135 $\mathrm{KCl}, 3.5 \mathrm{MgCl}_{2}, 0.1 \mathrm{CaCl}_{2}$, 5 EGTA, 5 HEPES, 0-4 $\mathrm{Na}_{2} \mathrm{ATP}, 0-0.2$ $\mathrm{Na}_{2} \mathrm{GTP}, \mathrm{pH} 7.2(\mathrm{KOH}), 290 \mathrm{mOsm}$. For IHC recordings, the $\mathrm{K}$-methanesulfonate-based intracellular solution was used. Extracellular solution for afferent fiber and IHC recordings contained the following (in mM): $5.8 \mathrm{KCl}, 143-144 \mathrm{NaCl}, 0.9 \mathrm{MgCl}_{2}, 1.3 \mathrm{CaCl}_{2}, 0.7 \mathrm{NaH}_{2} \mathrm{PO}_{4}, 5.6$ glucose, 10 HEPES, 0-1 Na pyruvate, pH $7.4(\mathrm{NaOH}), 300 \mathrm{mOsm}$. Tetrodotoxin (TTX; $1-2 \mu \mathrm{M}$ ) was added to the extracellular solution to block voltage-gated sodium channels. In some recordings, EPSCs were compared in the absence and presence of 1-2 $\mu \mathrm{M}$ TTX. Data were pooled when no differences in EPSC waveform were observed. In solutions with elevated $\mathrm{K}^{+}$concentrations, equimolar $\mathrm{NaCl}$ was replaced with $\mathrm{KCl}$. Changes in extracellular solution were mediated by whole-bath perfusion or a local application pipette (100- $\mu \mathrm{m}$-diameter opening) placed near the row of IHCs. Chemicals and TTX were purchased from Sigma, and cyclothiazide (CTZ) and 2,3-dioxo-6-nitro-1,2,3,4tetrahydrobenzo[f] quinoxaline-7-sulfonamide (NBQX) were purchased from Tocris Bioscience. Holding voltages (corrected for measured liquid junction potentials) were -84 or $-94 \mathrm{mV}$ (supplemental Table 1, available at www.jneurosci.org as supplemental material). Series resistance was calculated from capacitative transients in response to $10 \mathrm{mV}$ hyperpolarizing voltage steps. Average series resistance was $35 \mathrm{M} \Omega$, with values ranging from 20 to $57 \mathrm{M} \Omega$. Membrane capacitance ranged between 0.4 and $1.8 \mathrm{pF}$. The time constant of the clamp was $\sim 10-60 \mu \mathrm{s}$. Series resistance errors were not compensated for; with a series resistance of 35 $\mathrm{M} \Omega$ and an EPSC amplitude of $375 \mathrm{pA}$ (mode of the EPSC amplitude distribution at $\mathrm{P} 19-21$ ), the series resistance error would be $13 \mathrm{mV}$ and the EPSC amplitude would be underestimated by 14\% (estimated from the slope of the IV relation of EPSCs).

Whole-cell recordings were stable for 15-60 min. Recordings commenced with $5.8 \mathrm{mM} \mathrm{K}^{+}$in the external solution. Under these conditions the IHC membrane potential was defined as being "at rest," and the EPSC rate as "spontaneous rate," when recorded. Afferent fiber recordings were initially identified by their typical current voltage relation. Some fibers had little ( $\ll 1$ EPSCs/s) or no synaptic activity in $5.8 \mathrm{mM} \mathrm{K}^{+}$ externally. In these cases, IHCs were depolarized with 15 or $40 \mathrm{~mm}$ extracellular $\mathrm{K}^{+}$to depolarize the IHC and induce higher rates of release (see supplemental Table 1, available at www.jneurosci.org as supplemental material, for recording conditions of individual fibers). For this study, data were pooled from recordings in $5.8,15$, and $40 \mathrm{~mm} \mathrm{~K}^{+}$, as EPSC amplitude distributions were independent of changes in hair cell depolarization (Glowatzki and Fuchs, 2002; Goutman and Glowatzki, 2007) (see Fig. 7). The membrane potential of IHCs from P19-21 rats, recorded in the current-clamp configuration of the patch-clamp technique, depolarized from $-59 \pm 1 \mathrm{mV}$ in $5.8 \mathrm{~mm} \mathrm{~K}^{+}$to $-21 \pm 1 \mathrm{mV}$ in $40 \mathrm{~mm} \mathrm{~K}^{+}$ ( $n=3$; data not shown).

Eleven of 31 fibers recorded from P19-21 rats presented a typical current-voltage relation but had little or no synaptic activity, even if hair cells were depolarized with 15 or $40 \mathrm{~mm}$ potassium in the external solution. Six of 31 fibers had large holding currents $(-500$ to $-1500 \mathrm{pA})$ and relatively high rates of EPSCs (4-40 EPSCs/s). It is not clear whether these observations represent subtypes of fibers or are due to recording artifacts. Fourteen recordings were included in the dataset, which had EPSC rates in $5.8,15$, or $40 \mathrm{~mm} \mathrm{~K}^{+}>0.05 / \mathrm{s}$ and holding currents that were $<300 \mathrm{pA}$ at holding potentials of -84 to $-94 \mathrm{mV}$.

Measurements were acquired using pCLAMP 9.2 or 10.2 software in conjunction with a Multiclamp 700A or 700B amplifier (Molecular Devices), low-pass filtered at $10 \mathrm{kHz}$, and digitized at $50 \mathrm{kHz}$ with a Digidata 1322A. Data were analyzed using Clampfit (Molecular Devices), Origin (OriginLab), MiniAnalysis (Synaptosoft), Matlab (MathWorks), and Prism (Graphpad) software. EPSCs were detected using a routine in Minianalysis, with a threshold set at 3 times the value of the root mean square of the baseline noise and subsequently accepted by eye. Monophasic and multiphasic EPSCs were classified by eye. Although this method is subject to bias, in our hands it provided the least amount of error handling the widely varying waveforms. In a parallel approach, formalized criteria were developed to separate monophasic and multiphasic EPSCs, using the first derivative of the EPSC waveforms (supplemental Fig. 1, available at www.jneurosci.org as supplemental material). This approach was useful in defining a threshold for the level of deflection in the rising phase that would classify an EPSC as multiphasic. Also, larger deflections in the decay phase were detected well. However, as waveforms were highly variable, especially during the noisier decay phases, a subset of EPSCs that was not classified well by the formalized approach still required sorting by eye. A subset of data was analyzed by both methods and $<5 \%$ of EPSCs were found to be classified differently, validating both methods as reasonable approaches.

Data are expressed as mean $\pm \mathrm{SD}$; means are average values of mean or median values calculated for each cell, representing the average across cells. For statistical analyses, data were tested for normality using D'Agostino and Pearson normality test and parametric or nonparametric tests applied accordingly. Where two parameters were compared $t$ tests or nonparametric equivalents were used; for two parameters recorded within the same cell paired tests were used. Where more than two parameters were compared ANOVAs were used. Level of statistical significance was $p<0.05$. Where developmental changes were analyzed statistical analyses compared P8-11 data with P19-21 data. Data for the two fibers recorded at $\mathrm{P} 60$ were not included in this analysis.

\section{Results \\ EPSCs are mediated by AMPA receptors in immature and hearing animals}

To investigate changes in synaptic transmission during maturation, whole-cell patch-clamp recordings were made from afferent fiber terminals at their point of contact with IHCs in excised apical cochlear coils. EPSCs were analyzed for two age ranges, for immature rats $(\mathrm{P} 8-11)$, before the onset of hearing that occurs around P12 in rats (Müller, 1991b), and for hearing rats (P1921). Some properties of EPSCs from afferent boutons of immature rats (P8-11) have been published previously (Glowatzki and Fuchs, 2002; Goutman and Glowatzki, 2007). However, here a larger dataset is provided for this age range for additional characterization. A preparation from a P19 rat, as visualized on a 
monitor during the experiment, is shown in Figure $1 A$. The basal region of six IHCs is shown with a number of fibers visible beneath the IHCs. Asterisks indicate possible recording sites. Representative EPSCs recorded from an afferent terminal of a P19 rat cochlea are presented in Figure $1 B$. For this recording, the extracellular concentration of potassium was elevated from 5.8 to $40 \mathrm{~mm}$ to depolarize the IHC and increase the EPSC firing rate. For all fibers analyzed (recorded with 5.8, 15, or $40 \mathrm{~mm}$ potassium in the extracellular solution), EPSC rates ranged between 0.06 and 35.4 EPSCs/s. Recording conditions and properties for individual fibers are given in supplemental Table 1, available at www.jneurosci.org as supplemental material.

As shown previously (Glowatzki and Fuchs, 2002), EPSCs in immature afferent fibers are mediated by AMPA receptors: EPSCs reversed around $0 \mathrm{mV}$, were blocked by CNQX and modulated by the AMPA-specific modulator cyclothiazide (CTZ). Data presented here confirm this result. Before hearing onset, at P8-11, EPSCs were completely blocked by the AMPA receptor blocker NBQX (at $10 \mu \mathrm{M}$, $n=6$, data not shown). At P19-21, block by NBQX $(1-50 \mu \mathrm{M})$, was almost complete $(n=5)$ (Fig. $1 B)$. The current voltage relation for average EPSCs was close to linear and reversed at $\sim 0 \mathrm{mV}(n=2)$ (Fig. $1 D, E)$. In the presence of $100 \mu \mathrm{M}$ CTZ EPSC kinetics were significantly slower; the time constant of decay slowed from $0.58 \pm 0.3 \mathrm{~ms}$ to $2.19 \pm 0.6 \mathrm{~ms}(p<$ $0.0001 ; n=1$ afferent; only monophasic EPSCs analyzed; 2314 control EPSCs versus 1172 EPSCs in $100 \mu \mathrm{M}$ CTZ) and EPSC amplitudes became larger (309 土 $130 \mathrm{pA}$ in control versus $468 \pm 137 \mathrm{pA}$ in CTZ $(p<0.0001)$ (Fig. $1 C)$. Hence, under recording conditions used here, EPSCs at the IHC afferent synapse in both age ranges, before and after hearing onset, were mediated by AMPA type glutamate receptors.

\section{Relative contributions of monophasic and multiphasic EPSCs} change after hearing onset

Monophasic EPSCs were defined as exhibiting sharp rise times and monoexponential decays and multiphasic EPSCs as showing inflections during rising and/or decaying phases. Examples are shown in Figure $2 A, B$. Multiphasic EPSCs are common in the immature rat cochlea (Glowatzki and Fuchs, 2002; Goutman and Glowatzki, 2007), but represent $<5 \%$ of EPSCs in the adult frog papilla (Keen and Hudspeth, 2006; Li et al., 2009). These results raised the question whether multiphasic EPSCs represent a feature of the immature synapse in the rat cochlea. To investigate whether multiphasic EPSCs still occur in recordings from hearing rats, EPSC waveforms from afferent boutons of P8-11 rats (12 fibers), P19-21 rats (14 fibers), and P60 rats (2 fibers) were examined. For classification of monophasic versus multiphasic EPSCs, see Materials and Methods and supplemental Figure 1, available at www.jneurosci.org as supplemental material.

At every age and in every fiber examined, both monophasic and multiphasic EPSCs were observed (Fig. 2A,B). However, when data were pooled for P8-11 and compared with pooled data from P19-21 rats, there was a significant increase in the percentage of monophasic EPSCs in afferent boutons of hearing animals compared to that in immature animals ( $71 \pm 18 \%$ compared to $56 \pm 15 \% ; p=0.032$ ) (Fig. $2 C$ ). The range for the percentage of monophasic EPSCs across individual fibers was similarly wide for afferents from P8-11 (34-86\%) and P19-21 rats $(30-87 \%)$ (Fig. $2 D)$. However, at P8 -11 only 2 of 12 fibers had $>75 \%$ of EPSCs classified as monophasic, whereas at P1921,9 of 14 fibers had $>75 \%$ of EPSCs classed as monophasic. In two fibers from adult (P60) rats, monophasic EPSCs comprised $52 \%$ and $74 \%$ of the total. In summary, after hearing onset, more 
A

MONOPHASIC EPSCS

P10 EY86

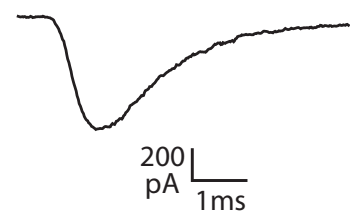

B

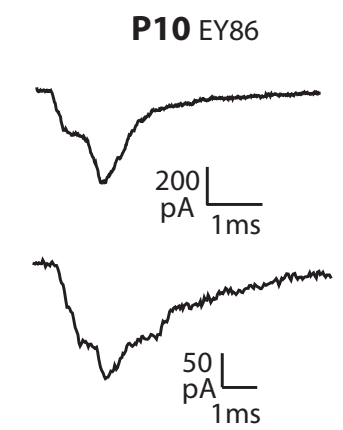

C

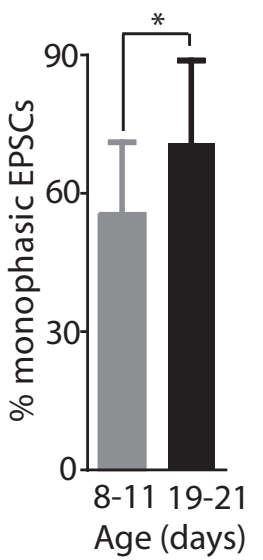

$$
\text { P20 LG96 }
$$

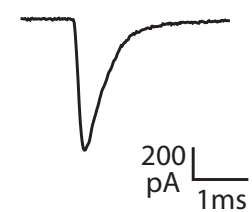

MULTIPHASIC EPSCS
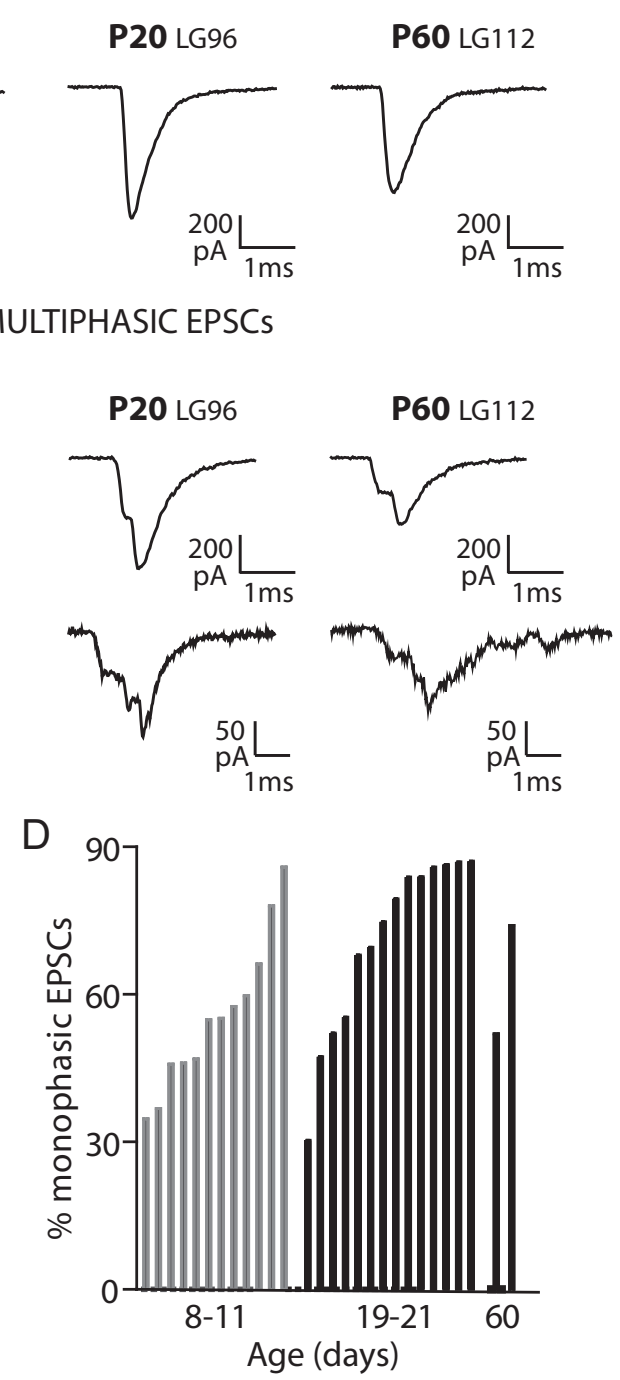

Figure 2. Afferent recordings from hearing rats exhibit on average more monophasic EPSCs compared to immature rats. $\boldsymbol{A}, \boldsymbol{B}$, Exemplar EPSCS from afferent boutons of a P10, a P20, and a P60 rat. EPSCs with a steady rising phase and monoexponential decay were classified as monophasic $(\boldsymbol{A})$. EPSCs with inflections on rising and/or decaying phases were classified as multiphasic $(\boldsymbol{B})$. C, Quantification of the mean percentage of monophasic EPSCs in afferent fibers of P8-11 and P19-21 rat cochleae (9289 EPSCS in 12 fibers of P8-11 rats and 10,500 EPSCs from 14 fibers of P19-21 rats). The percentage of monophasic EPSCs increased significantly from $56 \%$ at P8 -11 to $71 \%$ at P19-21 ( $p=0.024)$. $D$, The percentage of monophasic EPSC in individual fibers from P8-11; P19-21 and P60 cochleae ranked from lowest to highest percentage in each age group. Two of 12 afferents from P8 -11 rats had $>75 \%$ monophasic EPSCS, whereas 9 of 14 afferents from P19-21 rats had $>75 \%$ monophasic EPSCs. Note that four fibers from P19-21 rats had relatively low percentages of monophasic EPSCs. In two recordings from afferent boutons of P60 rat cochleae monophasic EPSCs were 52\% and 74\% (6170 EPSCs total).

fibers exhibited higher percentages of monophasic EPSCs. However, the continued presence of significant numbers of multiphasic EPSCs at P19-21 and even at P60 emphasizes that this type of EPSC is not simply a developmental feature and its impact on the afferent fiber's firing pattern in hearing animals needs to be considered.

\section{EPSC kinetics are faster after hearing onset}

Speeding of EPSC kinetics is a common phenomenon during maturation of glutamatergic synapses, including auditory synapses (Bellingham et al., 1998; Taschenberger and von Gersdorff, 2000; Brenowitz and Trussell, 2001; Wall et al., 2002; Koike-Tani et al., 2005). Fast kinetics are important for hearing, where accurate representation of timing information is vital.
EPSC kinetics were compared in afferent fibers from immature and hearing rats. For monophasic EPSCs, the time to peak, and the time constant of decay ( $\tau$ decay) were significantly faster in hearing animals (Fig. 3A-E). Time to peak was $0.58 \pm$ $0.1 \mathrm{~ms}$ at $\mathrm{P} 8-11(n=12)$, and twofold faster at P19-21 $(0.29 \pm 0.1 \mathrm{~ms}, n=14)$ $(p<0.0001) . \tau$ decay decreased by a factor of 3 from $1.4 \pm 0.6 \mathrm{~ms}$ at $\mathrm{P} 8-11$ to $0.5 \pm 0.2 \mathrm{~ms}$ at P19-21 ( $p<0.0001)$. Speeding of EPSC kinetics occurred across the entire amplitude range. This is demonstrated in Figure $3 E$ for EPSCs from a P8 and a P20 rat, where decay time constant is plotted against EPSC amplitude for every monophasic EPSC. Additionally, the monophasic EPSC waveform was less variable in afferents from hearing animals; the coefficient of variation for $\tau$ decay was smaller in the more mature fibers $(30 \pm 19 \%$ at $\mathrm{P} 19-21$ versus $61 \pm$ $56 \%$ for P $8-11 ; p=0.037)$. For multiphasic EPSCs, the time to peak was measured from the onset to the maximal EPSC amplitude. Again, the time course was significantly faster in afferent fibers from hearing rats. The time to peak was $1.1 \pm$ $0.2 \mathrm{~ms}$ at $\mathrm{P} 8-11(n=12)$ and almost twice as fast at $0.6 \pm 0.1 \mathrm{~ms}$ at $\mathrm{P} 19-21(n=14)$ $(p<0.0001)$. At both ages, the time to peak for multiphasic EPSCs was approximately a factor of two significantly slower than the time to peak for monophasic EPSCs (P8-11: $p<0.001$; P19-21: $p<$ $0.001)$. The half-width of multiphasic EPSCs decreased by a factor of two from $1.4 \pm 0.6 \mathrm{~ms}$ in $\mathrm{P} 8-11$ rats to $0.7 \pm 0.3 \mathrm{~ms}$ in $\mathrm{P} 19-21$ rats $(p=0.003)$ (Fig. $3 F)$. Again, the faster time course of multiphasic EPSCs in hearing rats occurred across the entire EPSC amplitude range (Fig. $3 G$ ). The coefficient of variation for multiphasic half-width was similar for both age ranges (prehearing: $66 \pm 24 \%$; hearing: $53 \pm 16 \%$ ); multiphasic EPSCs were as variable in shape after hearing onset. Kinetics for both monophasic and multiphasic EPSCs were similar in afferents from P19-21 rats and the two fibers recorded from P60 rats (Fig. $3 D, F)$ suggesting that for this feature $\mathrm{P} 19-21$ fibers have reached maturity.

As kinetics of monophasic EPSCs get faster in hearing animals and multiphasic EPSCs sped up to a similar degree, a postsynaptic mechanism likely underlies the change. That a change in coordination of release may also occur with age is reflected in the lower percentage of multiphasic EPSCs in more mature animals. Therefore, these data suggest that both presynaptic and postsynaptic changes occur with maturation.

\section{On average, EPSC amplitudes are larger after hearing onset} To compare EPSC amplitude distributions before and after hearing onset, in a first step, EPSC amplitudes were pooled from all 
P8-11 fibers (9289 EPSCs from 12 fibers) and all P19-21 fibers (10,500 EPSCs from 14 fibers) (Fig. $4 A, B$ ). For this analysis, data were included from monophasic and multiphasic EPSCs. For every multiphasic EPSC, the maximal peak was measured for the EPSC amplitude (Fig. 4H). The pooled EPSC amplitude distribution from immature afferents largely resembled those published previously (Glowatzki and Fuchs, 2002) with a modal peak at $\sim 30 \mathrm{pA}$ and a highly skewed distribution extending to $\sim 800 \mathrm{pA}$ (Fig. $4 A$ ). Additionally, a less prominent peak at $\sim 210$ pA was discernable. However, for pooled data from hearing animals, a strikingly different EPSC amplitude distribution was found. A smaller peak at $\sim 50 \mathrm{pA}$ was dwarfed by a larger modal peak at $\sim 375$ pA (Fig. 4B). The average median EPSC amplitude was significantly larger in afferents from P19-21 rats at $287 \pm 40 \mathrm{pA}$ $(n=14)$ compared to $134 \pm 21 \mathrm{pA}$ in P8-11 rats $(n=12)(p=0.003)$. The overall increase in EPSC amplitude in hearing animals can also be discerned by comparing the cumulative fractions of EPSC amplitudes plotted for P8-11 and P19-21 afferents (Fig. 4C). This analysis most likely underestimated the difference in EPSC amplitudes comparing both age ranges. In afferents from hearing rats a significant proportion of EPSCs were greater than several hundred $\mathrm{pA}$, where current sizes might have been underestimated due to uncompensated series resistance errors (by $\sim 14 \%$ at $375 \mathrm{pA}$, see Materials and Methods). The overall increase of EPSC amplitude with age could be one factor underlying changes in auditory nerve fiber firing properties before and after hearing onset (see Discussion).

The shape of EPSC amplitude distributions is determined by the relative contributions of monophasic and multiphasic EPSCs

To understand how monophasic and multiphasic EPSCs contribute to the EPSC amplitude distributions, pooled distributions were separated for P8-11 and P19-21 by EPSC type (Fig. $4 D-G$ ). This analysis illustrates that the modal peak of the pooled amplitude distribution for P8-11 fibers was dominated by multiphasic EPSCs and that for P19-21 fibers by monophasic EPSCs. At P8-11, the distribution of multiphasic EPSCs had a peak at $\sim 24 \mathrm{pA}$, similar to the modal peak at $\sim 30 \mathrm{pA}$ of the summed distribution, and was highly skewed with amplitudes up to $\sim 800 \mathrm{pA}$ (Fig. $4 D$ ). The distribution of monophasic EPSCs was bimodal, with peaks at $\sim 30 \mathrm{pA}$ and $\sim 210 \mathrm{pA}$ (Fig. $4 F$ ), contributing to both peaks of the summed distribution (Fig. 4A). At P19-21, the amplitude distribution of monophasic EPSCs (Fig. 4G) had remarkably similar features compared to the summed distribution (Fig. 4B).
MONOPHASIC EPSCS

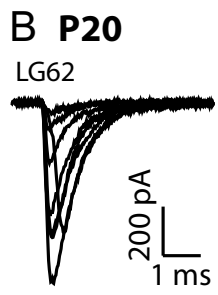

C Scaled averages
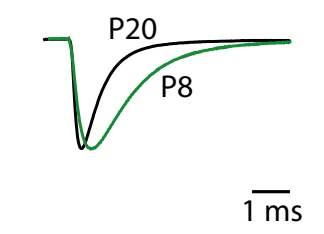

E
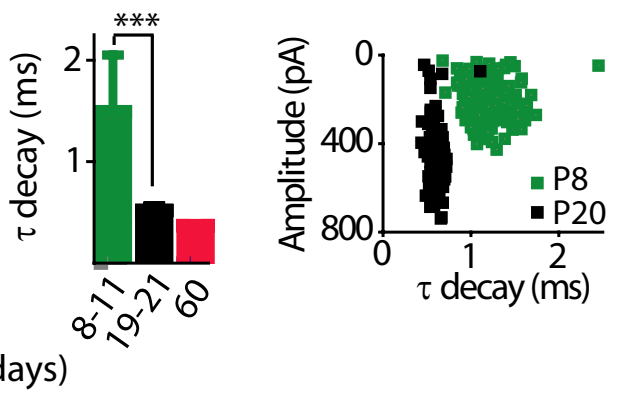

MULTIPHASIC EPSCS
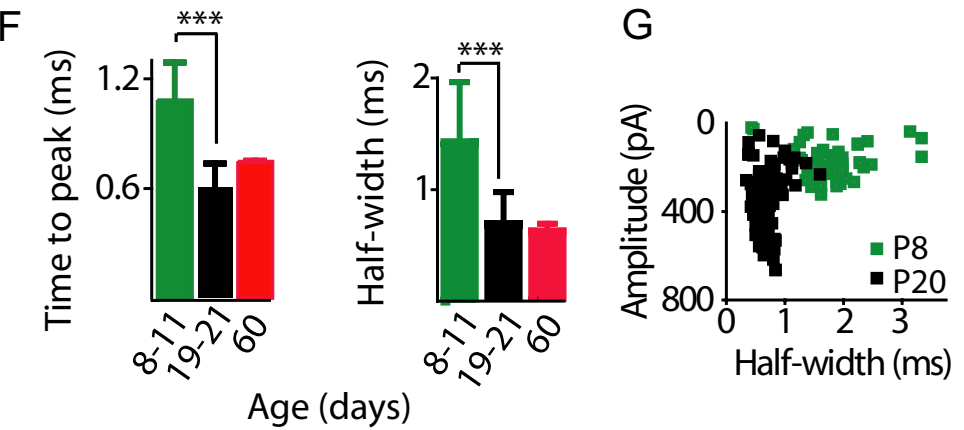

Figure 3. EPSC kinetics are significantly faster in afferents from hearing versus immature rat cochleae. $\boldsymbol{A}, \boldsymbol{B}$, Selection of monophasic EPSCs recorded from a P8 $(\boldsymbol{A})$ and a P20 (B) afferent at $-94 \mathrm{mV}$ with $5.8 \mathrm{~mm} \mathrm{~K}^{+}$extracellularly. $\boldsymbol{C}$, Normalized average EPSC waveforms for the two cells presented in $\boldsymbol{A}$ and $\boldsymbol{B}$ (EPSCs averaged: $P 8 n=336$, green; $P 20 n=216$, black). $\boldsymbol{D}$, Average time to peak and $\tau$ decay presented for monophasic EPSCs from 12 boutons of P8 -11 (time to peak: $0.58 \pm 0.1$ ms; decay: $1.4 \pm 0.6$ ms; 5078 EPS(s), 14 boutons of P19-21 (time to peak: $0.29 \pm 0.1 \mathrm{~ms}$; decay $0.5 \pm 0.2 \mathrm{~ms} ; 6782$ EPSCs), and 2 boutons of P60 (time to peak: $0.28 \pm 0.002 \mathrm{~ms}$; decay: $0.37 \pm 0.002 \mathrm{~ms} ; 3796 \mathrm{EPSCs}$ ) rats. EPSC kinetics were significantly faster in boutons from hearing rats (time to peak and $\tau$ decay $p<0.0001$; comparing P8 -11 and P19-21 datasets). $\boldsymbol{E}$, Plot of $\tau$ decay against EPSC 作 $\boldsymbol{A}$ and $\boldsymbol{B}$. EPSCs in hearing afferents were significantly faster across the entire amplitude range. Monophasic EPSC waveforms were more uniform in boutons from hearing animals illustrated by the less variable decay time constant for the P20 afferent. $\boldsymbol{F}$, Average ms; 4616 EPSCs), 14 P19-21 (time to peak: $0.6 \pm 0.1 \mathrm{~ms}$; half-width: $0.7 \pm 0.3 \mathrm{~ms} ; 2525$ EPSCs), and 2 P60 (time to peak: $0.8 \pm$ $003 \mathrm{~ms}$; half-width: $0.6 \pm 0.1 ; 2374$ EPSCs) rats. Multiphasic EPSCs were significantly faster in boutons from hearing rats (time amplitude for every multiphasic EPSC from one P8 afferent (green squares) and one P20 afferent (black squares), same fibers as in $\boldsymbol{A}$ and $\boldsymbol{B}$. Multiphasic EPSCs were significantly faster across the entire amplitude range.

The nearly Gaussian amplitude distribution of monophasic EPSCs had a peak at $\sim 375 \mathrm{pA}$, and a second, much smaller peak at $\sim 50$ pA. For multiphasic EPSCs, the modal peak at $\sim 24 \mathrm{pA}$, found at P8-11, was lost at P19-21. For both, monophasic and multiphasic EPSCs, the average median EPSC amplitude shifted to larger values with age: For multiphasic EPSCs from $97 \pm 62 \mathrm{pA}$ to $217 \pm 121 \mathrm{pA}(p=0.005)$ and for monophasic EPSCs from $155 \pm 99 \mathrm{pA}$ to $308 \pm 124 \mathrm{pA}(p=0.002)$. In summary, the shift in the EPSC amplitude distribution to a higher modal peak with age was based on the following changes: First, a shift in the relative contribution of multiphasic and monophasic EPSCs occurred with age, resulting in a shift of the modal peak from $\sim 30$ 

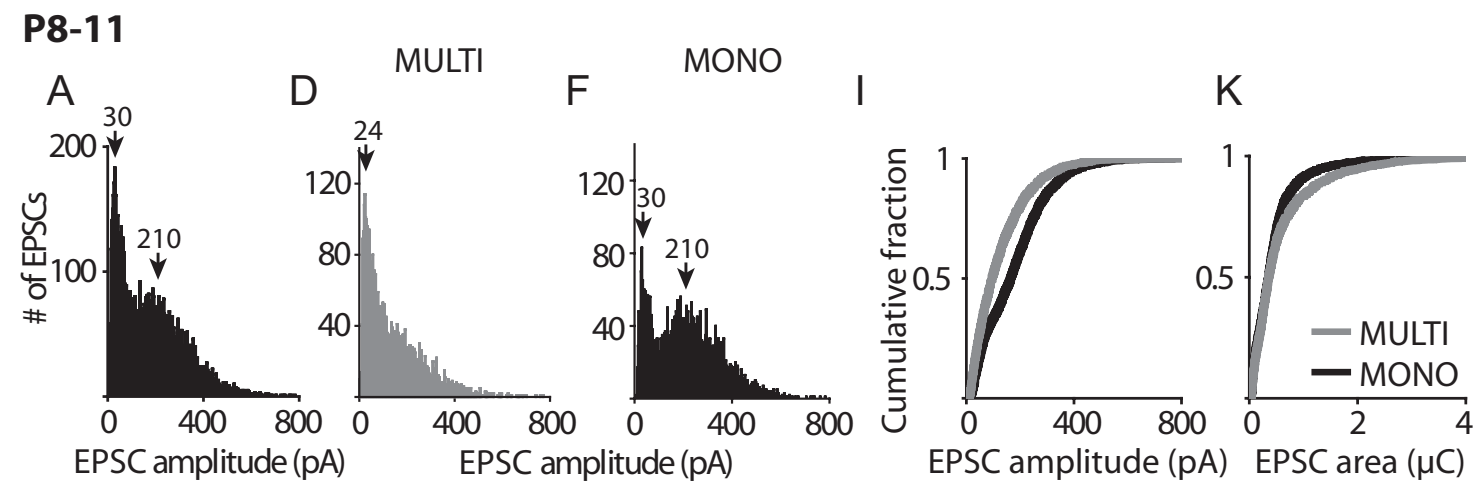

\section{P19-21}
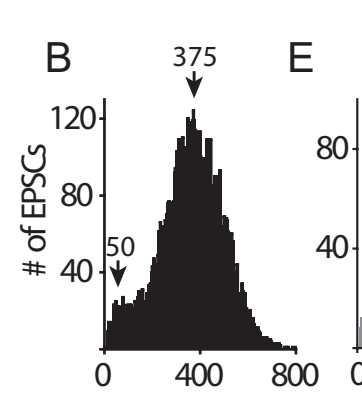

MULTI

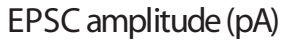

C
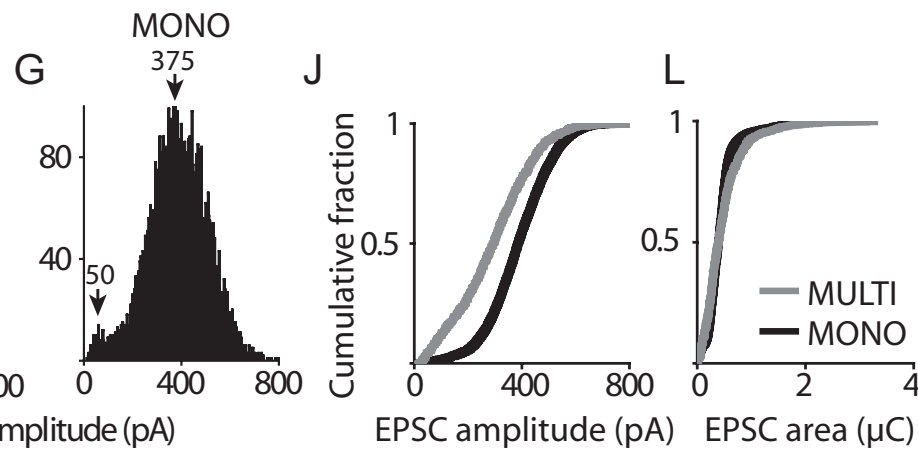

EPSC amplitude (pA) EPSC area $(\mu \mathrm{C})$

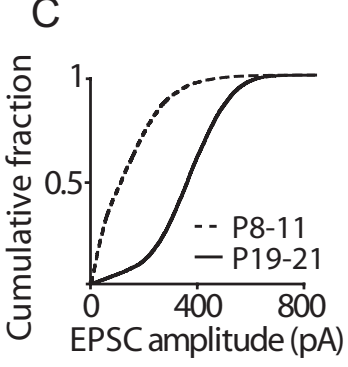

$\mathrm{H}$

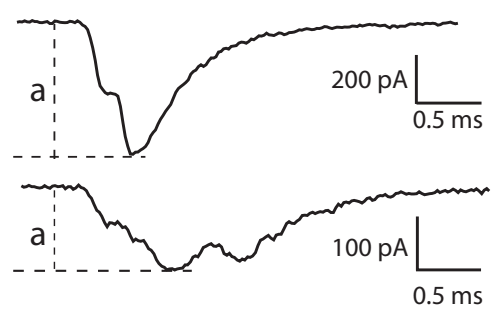

Figure 4. On average, EPSC amplitudes in afferent fibers shift to higher values in hearing animals. $\boldsymbol{A}, \boldsymbol{B}$, Pooled amplitude distributions for EPSC amplitudes from all P8 -11 afferents ( $\boldsymbol{A} ; \boldsymbol{n}=12$ cells 9289 EPSCs) and P19-21 afferents ( $\boldsymbol{B} ; n=14$ cells 10,500 EPSCs). For multiphasic EPSCs amplitude was measured from baseline to the maximal amplitude (see $\boldsymbol{H}$ ). A shift in the modal EPSC amplitude is apparent from $\sim 30$ pA in P8-11 afferents to $\sim 375$ pA in P19-21 afferents. C, Cumulative amplitude distribution for EPSCs from all P8-11 and all P19-21 afferents pooled. D-G, Amplitude distribution for only multiphasic $(\boldsymbol{D}, \boldsymbol{E})$ or only monophasic $(\boldsymbol{F}, \boldsymbol{G})$ EPSCs from all P8-11 afferent fibers or from all P19-21 fibers. Bin width for all histograms is 3 pA. Arrowheads and numbers indicate amplitudes for peaks of distributions. $\boldsymbol{H}$, Examples of how EPSC amplitudes were measured for multiphasic EPSCs, dashed lines indicate EPSC amplitude (a). $\boldsymbol{I}, \boldsymbol{J}$, Cumulative EPSC amplitude plots for multiphasic and monophasic EPSC from all P8-11 $(\boldsymbol{I})$ and all P19-21 (J) fibers pooled. $\boldsymbol{K}, \boldsymbol{L}$, Cumulative area plots for multiphasic and monophasic EPSCs from all P8-11 $(\boldsymbol{K})$ and all P19-21 $(\boldsymbol{L})$ fibers pooled.

$\mathrm{pA}$ to $\sim 375 \mathrm{pA}$. This result can be interpreted as a shift to a higher level of coordination of release events with age; changing from the preferential release of single vesicles at P8-11 to approximately seven to nine vesicles at P19-21 assuming that the first peak in the monophasic distribution of $\sim 50 \mathrm{pA}$ represents the quantal size at P19-21 (see below). Second, both peaks in the monophasic distributions shifted to larger amplitudes with age; from $\sim 30 \mathrm{pA}$ to $\sim 50 \mathrm{pA}$ for the smaller peak and from $\sim 210 \mathrm{pA}$ to $\sim 375 \mathrm{pA}$ for the larger peak. For both peaks, this shift could be interpreted as an increase in quantal size with age and for the larger peak, a change in the preferred level of coordination could also have occurred. For multiphasic EPSCs, also a change to larger amplitudes with age occurred, most likely based on similar mechanisms.

In hearing animals, the median EPSC amplitude differs; however, the charge transfer is similar for monophasic and multiphasic EPSCs

Cumulative fraction plots compare the EPSC amplitude distributions of monophasic and multiphasic EPSCs (Fig. 4I,J). At both ages, there is a trend toward larger amplitudes for monophasic EPSCs. At P8-11, the average median EPSC amplitudes of monophasic and multiphasic EPSCs do not differ significantly (P8-11 monophasic: $161 \pm 108 \mathrm{pA} ; n=12$; versus multiphasic: $119 \pm 134 \mathrm{pA} ; n=14)$. However, at P19-21, the average median EPSC amplitude of monophasic EPSCs was significantly larger compared to multiphasic EPSCs (monophasic: $295 \pm 130 \mathrm{pA}$, multiphasic: $218 \pm 128 \mathrm{pA} ; p=0.0008$ ). This difference in size could be physiologically relevant, as multiphasic EPSPs might have a lower chance of reaching threshold for action potential (AP) generation compared to monophasic EPSPs (see Discussion).

The smaller amplitude, multiphasic EPSCs at P19-21 could result from the release of fewer vesicles than those contributing to larger monophasic EPSCs. Alternatively, smaller amplitudes could be due to a similar number of vesicles released in a less coordinated manner. To compare the relative number of vesicles released in multiphasic versus monophasic EPSCs, every EPSC was integrated, thus calculating its charge transfer. The charge transfer for monophasic and multiphasic EPSCs were 
compared within the age groups $\mathrm{P} 8-11$ and P19-21, where kinetics were constant (Fig. $4 K, L$ ). These comparisons were performed under the assumption that postsynaptic unitary events sum linearly within multiphasic and monophasic EPSCs. For both ages, the cumulative distributions of charge transfer closely overlapped for monophasic and multiphasic EPSCs. The average median charge transfer for monophasic versus multiphasic EPSCs was not significantly different at both developmental stages (P8-11 monophasic: $411 \pm 285 \mathrm{nC}$, multiphasic: $422 \pm 357 \mathrm{nC}$; P19-21 monophasic: $314 \pm 157 \mathrm{nC}$, multiphasic: $310 \pm 170 \mathrm{nC})$. These data suggest that even at P19-21, where median EPSC amplitudes are different for both EPSC types, for any given synapse, on average the same numbers of vesicles were released during monophasic and multiphasic EPSCs. It is therefore highly likely that both monophasic and multiphasic EPSCs draw from the same pool of vesicles, but that multiphasic EPSCs exhibit smaller amplitudes due to a less coordinate release.

The EPSC type, monophasic or multiphasic, is independent of the preceding time interval, EPSC area or amplitude

The mechanisms that determine whether a monophasic or multiphasic EPSC is activated are unknown. Here we examine whether the length of the preceding interval or the attributes of the preceding EPSC influenced whether a monophasic or multiphasic EPSC would occur. Recordings from the auditory nerve show that the timing of auditory nerve fiber discharge follows a near-Poisson process (Kiang et al., 1965). Interevent intervals for all EPSCs were analyzed for cells with $>650$ EPSCs (P8-11: $n=3$; P19-21: $n=5)$. Interval histograms decayed in an exponential manner (Fig. 5A,B), consistent with an underlying Poisson release process in which the probability of an EPSC is constant, independent of the time since the preceding EPSC. When analyzed separately, intervals before monophasic EPSCs were no different than those before multiphasic EPSCs for both age ranges (Fig. 5C,D). Furthermore, amplitudes and integrals of EPSCs preceding a monophasic EPSC were not different from those preceding a multiphasic EPSC for both age ranges.

The sequence of EPSCs for each fiber was further analyzed by comparing the probability of each EPSC type following either a monophasic or a multiphasic EPSC. This analysis revealed a slight, but significant increase in the probability for a multiphasic EPSC to occur after another multiphasic EPSC for P19-21 rats [All EPSCs: mean percentage multiphasic: $27 \pm 15 \%$; only EPSCs occurring after a multiphasic EPSC: mean percentage multiphasic: $37 \pm 17 \%$; $(p<0.01)]$. After a monophasic EPSC, there were no significant differences in the probability of monophasic or multiphasic EPSCs occurring compared to their respective overall percentages.

In summary, these results demonstrate that EPSCs occurred at random intervals and that the intervals before monophasic and multiphasic EPSCs were not different. Also, there was no correlation
P11

EY91

B

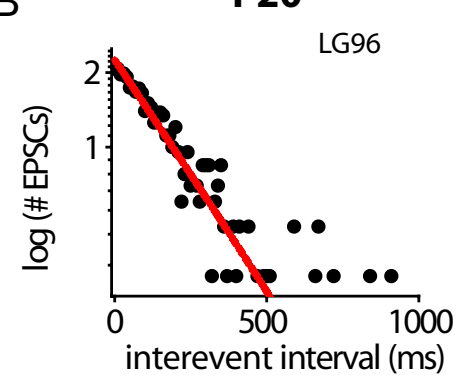

D

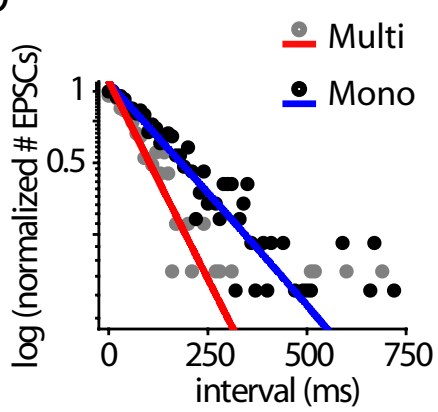

P20

$\stackrel{-M u l t i}{2}$
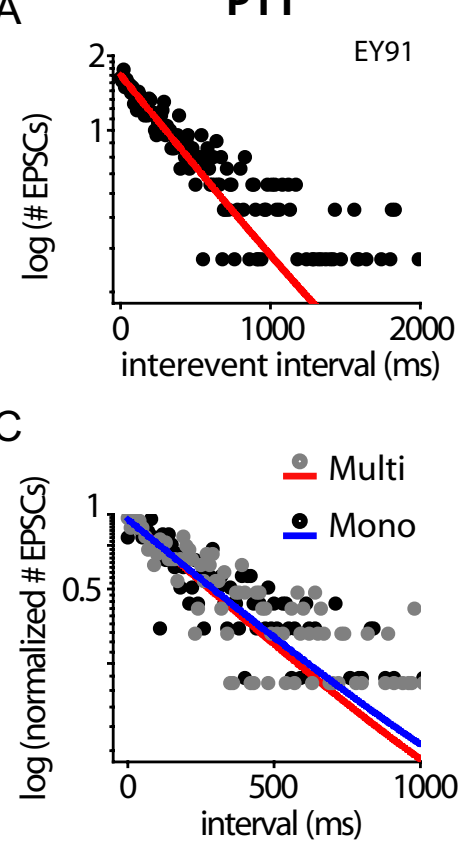

Figure 5. Monophasic and multiphasic EPSCs are distributed randomly in time. $\boldsymbol{A}, \boldsymbol{B}$, Interevent intervals plotted for all EPSCS 作 intervals or $\tau$ from exponential fits, median intervals: P8-11, $181 \pm 125$ ms (monophasic) versus $170 \pm 117$ (multiphasic); P19-21, $98 \pm 101 \mathrm{~ms}$ (monophasic) versus $92 \pm 136 \mathrm{~ms}$ (multiphasic)].

between the amplitude or area of the preceding EPSC and the type of the following EPSC. However, in hearing rats there was a $10 \%$ increase in the probability of observing a multiphasic EPSC following another multiphasic EPSC.

In hearing animals, fibers have more diverse EPSC amplitude distributions compared to fibers from immature rats

Figure $2 D$ demonstrates that the percentage of monophasic EPSCs is quite variable across individual fibers within the tested age ranges. Similarly, amplitude distributions varied widely across fibers within the age ranges, as illustrated in the cumulative EPSC amplitude plots for all individual fibers from P8-11 and P19-21 rats (Fig. 6). Amplitudes of monophasic and multiphasic EPSCs were considered for all fibers with $>60$ EPSCs in this analysis. Median EPSC amplitudes ranged from 19 to $251 \mathrm{pA}$ in 12 fibers from P8-11 rats and even wider, from 97 to 473 pA in 11 fibers from P19-21 rats. For further comparison, we classified fiber types according to their median EPSC amplitudes (Fig. 6A, $B$, dashed lines) (low-amplitude fiber: $<250 \mathrm{pA}$ and high-amplitude fiber: $>250 \mathrm{pA}$ ). Examples for these two fiber types are shown in Figure 6, $C$ and $D$. For low-amplitude fibers, distributions showed an initial peak at EPSC amplitudes of $<100 \mathrm{pA}$ and were highly skewed. For high-amplitude fibers, distributions were closer to a Gaussian distribution, showing a peak between 200 and 475 pA.

The majority of fibers from immature cochleae were of the low-amplitude type (11 of 12 fibers) and 1 of 12 was classed high amplitude (Fig. 6E). At P19-21, most fibers were categorized as high-amplitude fibers ( 8 of 11). High-amplitude fibers had a significantly higher percentage of monophasic EPSCs compared to low-amplitude fibers (Fig. 6C, D, F).

It is noteworthy that 3 of the 11 fibers at P19-21 were of the low-amplitude type. When the attributes of low-amplitude fibers 

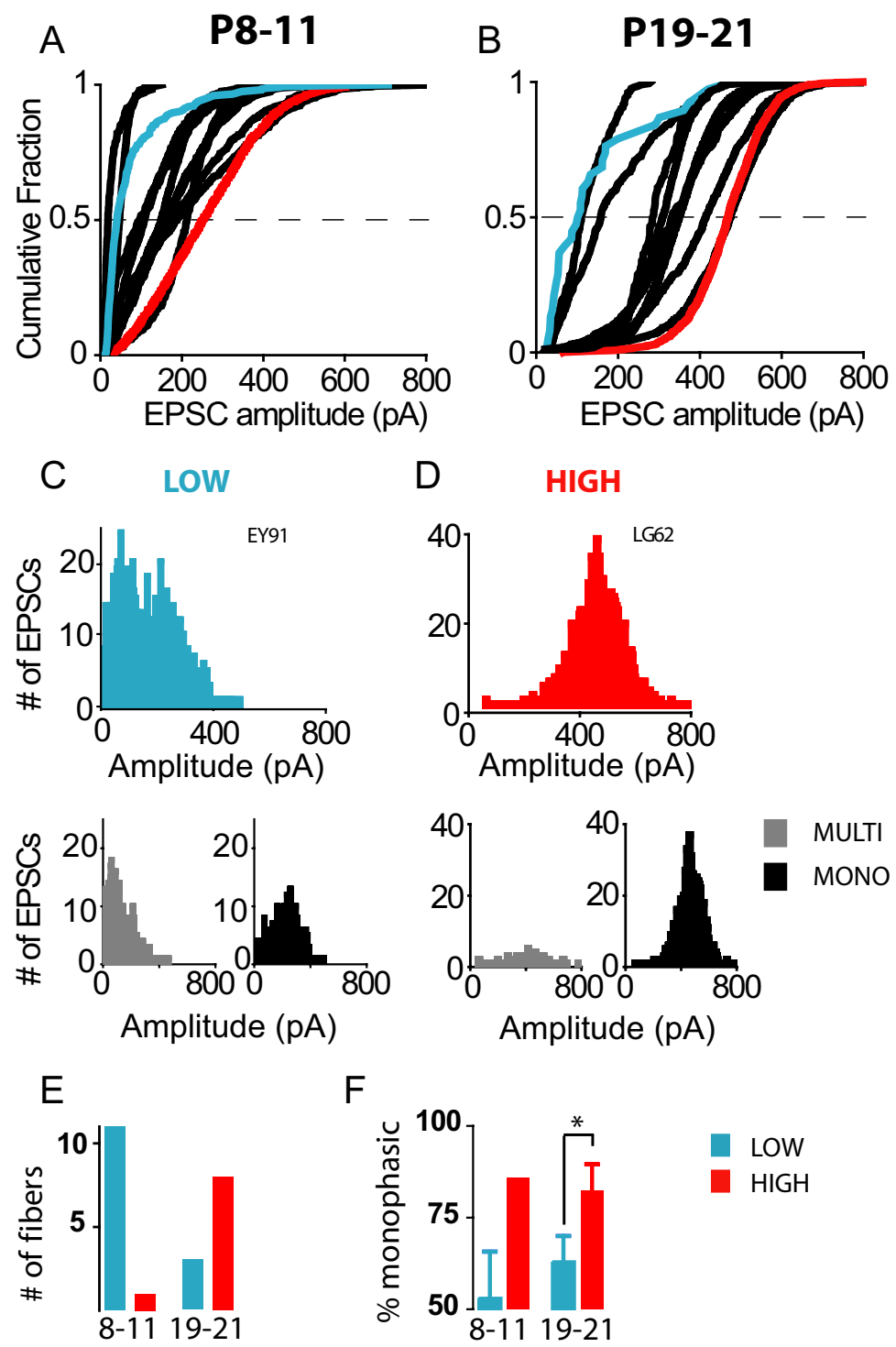

Figure 6. EPSC amplitude distributions for individual fibers are more diverse for hearing rats compared to immature rats. $\boldsymbol{A}, \boldsymbol{B}$, Cumulative EPSC amplitude plots for individual fibers from cochleae of P8-11 (A) and P19-21 $(\boldsymbol{B})$ rats. Fibers were classified as low amplitude or high amplitude by their median amplitude $(<250=10 \mathrm{w} ;>250=$ high). Representative fibers from each class are highlighted in the cumulative plots (blue $=$ low amplitude, red $=$ high amplitude). $\boldsymbol{C}, \boldsymbol{D}$, Individual amplitude histograms for exemplar low-amplitude and high-amplitude fibers, chosen from a P11 and a P20 rat respectively. Beneath each amplitude histogram, multiphasic and monophasic EPSC amplitude distributions are plotted separately. $\boldsymbol{E}$, Number of fibers classed as low and high amplitude from P8-11 and P19-21 rats. $\boldsymbol{F}$, Percentage of monophasic EPSCs in fibers categorized as low or high amplitude from P8-11 and P19-21 rats. At P19-21 where there were sufficient fibers in each category for statistical analysis there were significantly higher percentages of monophasic EPSCs in high-amplitude fibers compared to low-amplitude fibers [percentage monophasic: $63 \pm 7$ (3 low-amplitude fibers) versus $82 \pm 7$ ( 8 high-amplitude fibers); $p=0.003$ ].

from P8-11 and P19-21 were compared, the median EPSC amplitude and the percentage of monophasic EPSCs were not significantly different [amplitude: $123 \pm 65 \mathrm{pA}$ versus $118 \pm 34 \mathrm{pA}$; percentage monophasic: $53 \pm 13 \%$ versus $63 \pm 7 \%$; P8-11 $(n=$ 11) versus P19-21 $(n=3)$, respectively]. However, at P19-21, EPSC kinetics for low-amplitude fibers had become significantly faster ( $\tau$ decay: $1.54 \pm 0.8 \mathrm{~ms} ; 0.42 \pm 0.1 \mathrm{~ms}$; P8-11 lowamplitude versus P19-21 low-amplitude respectively; $p=0.02$ ), showing that these fibers exhibited mature features.

In summary, fibers with more diverse EPSC amplitude distributions were found in hearing rats compared to immature animals. Amplitude distributions of individual fibers are shaped by the relative contributions of monophasic and multiphasic events.
The wider range of EPSC amplitude distributions emerging with age could contribute to setting up diverse properties of auditory nerve fibers at the hair cell afferent synapse (see Discussion).

\section{The EPSC amplitude is independent of IHC depolarization}

For the immature cochlea, it has been demonstrated that the EPSC amplitude is independent of hair cell depolarization and the amount of calcium influx within the physiological range of activation; only the probability of release changes in a calcium-dependent manner (Glowatzki and Fuchs, 2002; Goutman and Glowatzki, 2007). This relationship was examined here for afferent fibers recorded from hearing rats. At P19-21, IHCs depolarize from $-59 \pm 1 \mathrm{mV}$ in $5.8 \mathrm{mM} \mathrm{K}^{+}$to $-21 \pm 1 \mathrm{mV}$ in $40 \mathrm{~mm} \mathrm{~K}^{+}(n=3$; data not shown). For three afferent fibers, one representative of the low-amplitude type and two of the high-amplitude type, amplitude distributions did not substantially shift or convert to a different fiber type with hair cell depolarization (Fig. 7A-C). Similarly, amplitude distributions did not shift for a P60 fiber, recorded in 5.8 and 40 $\mathrm{mM} \mathrm{K}^{+}$(Fig. 7D-F). Note that the amplitude distribution of the P60 fiber had two peaks, one dominated by smaller multiphasic and one by larger monophasic EPSCs (data not shown). Both peaks persisted with hair cell depolarization. For all four fibers presented, the median EPSC amplitude did not significantly change with IHC depolarization (Fig. 7A,D). Overall, comparing individual recordings acquired at different levels of hair cell depolarization, there was no correlation between the level of IHC depolarization and fiber type (supplemental Table 1, available at www.jneurosci. org as supplemental material). In summary, these data show that EPSC amplitude is independent of IHC depolarization and the amount of calcium influx for afferent fibers from hearing animals within the physiologically relevant range of IHC depolarization. This independence of EPSC amplitude from IHC depolarization justifies the comparison of afferent fibers with different levels of IHC depolarization (in 5.8-40 mM $\mathrm{K}^{+}$), as done in this study.

\section{Discussion}

Developmental changes in EPSC waveform could improve signaling acuity of auditory nerve fibers

With maturation, changes were found in the EPSC waveform that could improve auditory signaling acuity. Both monophasic and multiphasic EPSCs became twice as fast and monophasic EPSC waveforms became more uniform with age, which may decrease jitter during AP generation. In addition, the median EPSC amplitude more than doubled in afferent fibers from hearing rats, 
increasing the likelihood for synaptic events to reach AP threshold.

Speeding of EPSCs

Speeding of EPSCs with maturation has been shown at several synapses (Taschenberger and von Gersdorff, 2000; Brenowitz and Trussell, 2001; Futai et al., 2001; Wall et al., 2002; Takahashi, 2005) resulting from various mechanisms: changes in AMPA receptor composition, with a preference toward more strongly desensitizing flop splice variants (Mosbacher et al., 1994; Lawrence and Trussell, 2000; Wall et al., 2002; Koike-Tani et al., 2005); improved synchronization of vesicular release (Chuhma et al., 2001; Wall et al., 2002); changes in synaptic structure (Taschenberger et al., 2002; Cathala et al., 2005) and more effective glutamate clearance (Koike-Tani et al., 2005).

The kinetics of monophasic EPSCs changed uniformly across the entire amplitude range, including for the presumed uniquantal EPSCs. The simplest explanation for such a change would be a developmental change in expression of postsynaptic AMPA receptor subunits. GluA2/A3 and GluA4 have been localized at developing and adult IHC afferent synapses (Kuriyama et al., 1994; Luo et al., 1995; Matsubara et al., 1996; Knipper et al., 1997; Eybalin et al., 2004) and a developmental switch in subunits from GluA2/A3 to GluA4 (Knipper et al., 1997), and from GluA2-lacking to GluA2-containing (Eybalin et al., 2004) has been reported for the rat cochlea. Flip and flop mRNA for GluA2, A3 and A4 have been localized in adult rat cochlear ganglion cells (Niedzielski and Wenthold, 1995); however, developmental changes in splice variant expression have not been investigated. Regarding developmental changes in coordination of release, comparison of EPSC time to peak did not reveal an increased speeding of multiphasic compared to monophasic EPSCs. However, an improved synchronization of release with maturation is indicated by the presence of a higher percentage of larger monophasic EPSCs in hearing animals.

Increase in EPSC amplitude

Comparing pooled data for fibers at P8-11 and P19-21, the average median EPSC amplitude more than doubled and the mode of the amplitude distribution increased $>10$ times (from $\sim 30 \mathrm{pA}$ to $\sim 375 \mathrm{pA}$ ). We interpret the large shift in the mode as a change from preferential release of single vesicles in immature animals to preferential coordinate release of seven to nine vesicles in hearing animals. This calculation assumes that the first peak of the monophasic EPSC amplitude distribution represents the quantal size of $\sim 50 \mathrm{pA}$ in hearing animals, similar to that demonstrated at adult frog hair cell synapses (Li et al., 2009); it also accounts for underestimation of the modal amplitude in hearing animals by $\sim 14 \%$ due to series resistance error (see Materials and Methods). In addition to the change in modal amplitude, the first peak in the monophasic EPSC amplitude distributions shifted to a larger amplitude with age, from $\sim 30 \mathrm{pA}$ to $\sim 50 \mathrm{pA}$. This shift can be interpreted as a developmental increase in quantal size, as demonstrated at other synapses (Bellingham et al., 1998; Wall and
Usowicz, 1998; Brenowitz and Trussell, 2001; Futai et al., 2001; Joshi and Wang, 2002; Yamashita et al., 2003).

\section{Heterogeneity in amplitude distributions of individual} synapses may contribute to the diverse properties of auditory nerve fibers

Afferent fibers in this study showed widely ranging EPSC amplitude distributions. Immature fibers mostly presented lowamplitude distributions that were highly skewed with an initial peak at $<100 \mathrm{pA}$. In hearing animals, $>70 \%$ of fibers were classified as high amplitude, with a peak at $200-475$ pA. However, low-amplitude fibers also existed in hearing animals. How do the diverse EPSC amplitude distributions relate to firing properties of auditory nerve fibers? Preliminary data indicate that EPSC distributions translate into a similarly wide range of EPSP amplitudes (ranging from 1 to $30 \mathrm{mV}$ ), and that not every EPSP activates an AP (E. Yi and L. Grant, unpublished data). If multiphasic EPSPs reach threshold, they most likely trigger single APs; however, longer lasting multiphasic EPSPs may generate multiple APs. In vivo recordings from adult guinea pig afferent fibers also reported the occurrence of subthreshold EPSPs not only during the neural refractory period (Siegel, 1992). In immature fibers, with higher percentages of multiphasic EPSCs and smaller median EPSC amplitudes, less EPSPs may reach AP threshold compared to fibers in hearing animals. Additionally, in hearing animals, the on average smaller multiphasic EPSCs may be less likely to reach threshold compared to the larger monophasic EPSCs.

Auditory nerve fibers exhibit a wide range of spontaneous firing rates from $<1 /$ s to 140 /s (for review, see Ruggero, 1992; Taberner and Liberman, 2005). Founding studies in cats classified fibers as low $(<0.5 / \mathrm{s} ; \sim 15 \%$ of all fibers $)$, medium $(0.5-18 / \mathrm{s}$, 
$\sim 25 \%$ ), and high spontaneous rate $(>18 / \mathrm{s}, \sim 60 \%)$ (Liberman, 1978), and correlated fiber properties, such as threshold for activation by sound and dynamic range with spontaneous rate (Liberman, 1982). In many species, including rats, mice and gerbils, fibers with the highest spontaneous rates have the lowest thresholds and narrowest dynamic ranges at their characteristic frequency (and vice versa) (Ohlemiller and Echteler, 1990; el Barbary, 1991; Taberner and Liberman, 2005).

Variability in rates of vesicular release at individual active zones within the same IHC may be determined by the distribution and properties of calcium channels (Frank et al., 2009; Meyer et al., 2009). It is tempting to propose an additional mechanism: fibers with low EPSC amplitude distributions, as presented in this study, may represent fibers with low spontaneous rates, as most synaptic events may be insufficiently large to activate APs. In contrast, in fibers classified here as high amplitude, most EPSPs may activate APs and these fibers could correspond to high spontaneous rate auditory nerve fibers. Immature auditory nerve fibers exhibit low spontaneous rates and after hearing onset a wide range of spontaneous firing rates develops (Romand, 1984; Walsh and McGee, 1987; Müller, 1996). Similarly, EPSC amplitude distributions of immature fibers are mostly of the low-amplitude type, whereas in hearing animals the shape of the amplitude distributions diversifies. Most intriguingly, as EPSC amplitude distributions are shaped by the proportion of monophasic versus multiphasic EPSCs, we propose that the relative contribution of these two types of release events at individual synapses may set spontaneous rates and contribute toward the diversity of auditory nerve fibers.

\section{Two distinct modes of vesicle release at individual IHC ribbon synapses: possible mechanisms}

Monophasic and multiphasic EPSCs were found in every fiber recorded, the relative percentages of which varied across fibers. Charge transfer for both EPSC types was similar; therefore it is likely that they draw upon the same vesicle pool. The occurrence of monophasic versus multiphasic EPSCs was independent of the preceding time interval, EPSC charge transfer or amplitude. Thus any kind of exhaustion does not appear to influence whether a monophasic or multiphasic EPSC might occur. Furthermore, changes in presynaptic calcium influx with depolarization did not change EPSC amplitude distributions or the relative occurrence of monophasic versus multiphasic EPSCs. This calcium independence of EPSC amplitude appears rather specific for IHC afferent synapses, as studies investigating frog hair cell synapses report calcium-dependent EPSC amplitudes (Li et al., 2009; Rutherford and Roberts, 2009).

Regarding mechanisms supporting monophasic and multiphasic EPSCs and regulating their proportions at individual synapses, we can only speculate. Monophasic EPSCs with sharp rising phases, devoid of inflections, could be explained by the release of multiple vesicles in a compound fusion event, as shown for secretory cells (Alvarez de Toledo and Fernandez, 1990; Pickett and Edwardson, 2006; Vardjan et al., 2009). In support, at retinal bipolar cell ribbon synapses, elongated cisternal structures were found attached to presynaptic ribbons following stimulation (Matthews and Sterling, 2008). In compound events, vesicles could prefuse and subsequently fuse with the plasma membrane, or vesicles could fuse sequentially with a vesicle that has just fused with the plasma membrane. Sequential fusion steps could generate multiphasic EPSCs. The distribution of vesicular molecules facilitating vesicle-to-vesicle fusion may then set which type of release event might occur. At the calyx of Held, synaptotagmin II facilitates compound fusion (He et al., 2009). Perhaps molecules such as synaptotagmins or snapin, which are involved in synchronization of vesicular release at conventional synapses (Nishiki and Augustine, 2004; Sun et al., 2007; Pan et al., 2009) enable the unusual release process at IHC synapses. Furthermore, IHC calcium channel gating, with three closed and two open states, may provide a means for supporting different release modes (Zampini et al., 2010). In addition to compound fusion, monophasic or multiphasic EPSCs could result from the more or less simultaneous release of vesicles docked and primed at the plasma membrane. In the cat cochlea, size and complexity of presynaptic specializations differs for fibers with low and high spontaneous rates (Liberman, 1980; Liberman et al., 1990; Merchan-Perez and Liberman, 1996). However, diversity in molecular composition for these different fiber types has yet to be revealed.

\section{References}

Alvarez de Toledo G, Fernandez JM (1990) Compound versus multigranular exocytosis in peritoneal mast cells. J Gen Physiol 95:397-409.

Bellingham MC, Lim R, Walmsley B (1998) Developmental changes in EPSC quantal size and quantal content at a central glutamatergic synapse in rat. J Physiol 511:861-869.

Brenowitz S, Trussell LO (2001) Maturation of synaptic transmission at end-bulb synapses of the cochlear nucleus. J Neurosci 21:9487-9498.

Cathala L, Holderith NB, Nusser Z, DiGregorio DA, Cull-Candy SG (2005) Changes in synaptic structure underlie the developmental speeding of AMPA receptor-mediated EPSCs. Nat Neurosci 8:1310-1318.

Chuhma N, Koyano K, Ohmori H (2001) Synchronisation of neurotransmitter release during postnatal development in a calyceal presynaptic terminal of rat. J Physiol 530:93-104.

el Barbary A (1991) Auditory nerve of the normal and jaundiced rat. I. Spontaneous discharge rate and cochlear nerve histology. Hear Res 54: 75-90.

Eybalin M, Caicedo A, Renard N, Ruel J, Puel JL (2004) Transient Ca2+permeable AMPA receptors in postnatal rat primary auditory neurons. Eur J Neurosci 20:2981-2989.

Frank T, Khimich D, Neef A, Moser T (2009) Mechanisms contributing to synaptic $\mathrm{Ca} 2+$ signals and their heterogeneity in hair cells. Proc Natl Acad Sci U S A 106:4483-4488.

Futai K, Okada M, Matsuyama K, Takahashi T (2001) High-fidelity transmission acquired via a developmental decrease in NMDA receptor expression at an auditory synapse. J Neurosci 21:3342-3349.

Glowatzki E, Fuchs PA (2002) Transmitter release at the hair cell ribbon synapse. Nat Neurosci 5:147-154.

Goutman JD, Glowatzki E (2007) Time course and calcium dependence of transmitter release at a single ribbon synapse. Proc Natl Acad Sci U S A 104:16341-16346.

He L, Xue L, Xu J, McNeil BD, Bai L, Melicoff E, Adachi R, Wu LG (2009) Compound vesicle fusion increases quantal size and potentiates synaptic transmission. Nature 459:93-97.

Heidelberger R, Thoreson WB, Witkovsky P (2005) Synaptic transmission at retinal ribbon synapses. Prog Retin Eye Res 24:682-720.

Johnson SL, Franz C, Kuhn S, Furness DN, Rüttiger L, Münkner S, Rivolta MN, Seward EP, Herschman HR, Engel J, Knipper M, Marcotti W (2010) Synaptotagmin IV determines the linear $\mathrm{Ca} 2+$ dependence of vesicle fusion at auditory ribbon synapses. Nat Neurosci 13:45-52.

Joshi I, Wang LY (2002) Developmental profiles of glutamate receptors and synaptic transmission at a single synapse in the mouse auditory brainstem. J Physiol 540:861-873.

Keen EC, Hudspeth AJ (2006) Transfer characteristics of the hair cell's afferent synapse. Proc Natl Acad Sci U S A 103:5537-5542.

Kiang NY, Watanabe T, Thomas EC, Clark LF, eds (1965) Discharge patterns of single fibers in the cat's auditory nerve. Cambridge, MA: MIT.

Knipper M, Köpschall I, Rohbock K, Köpke AK, Bonk I, Zimmermann U, Zenner H (1997) Transient expression of NMDA receptors during rearrangement of AMPA-receptor-expressing fibers in the developing inner ear. Cell Tissue Res 287:23-41.

Koike-Tani M, Saitoh N, Takahashi T (2005) Mechanisms underlying developmental speeding in AMPA-EPSC decay time at the calyx of Held. J Neurosci 25:199-207.

Kuriyama H, Jenkins O, Altschuler RA (1994) Immunocytochemical local- 
ization of AMPA selective glutamate receptor subunits in the rat cochlea. Hear Res 80:233-240.

Lawrence JJ, Trussell LO (2000) Long-term specification of AMPA receptor properties after synapse formation. J Neurosci 20:4864-4870.

Lenzi D, von Gersdorff H (2001) Structure suggests function: the case for synaptic ribbons as exocytotic nanomachines. Bioessays 23:831-840.

Li GL, Keen E, Andor-Ardó D, Hudspeth AJ, von Gersdorff H (2009) The unitary event underlying multiquantal EPSCs at a hair cell's ribbon synapse. J Neurosci 29:7558-7568.

Liberman MC (1978) Auditory-nerve response from cats raised in a lownoise chamber. J Acoust Soc Am 63:442-455.

Liberman MC (1980) Morphological differences among radial afferent fibers in the cat cochlea: an electron-microscopic study of serial sections. Hear Res 3:45-63.

Liberman MC (1982) Single-neuron labeling in the cat auditory nerve. Science 216:1239-1241.

Liberman MC, Dodds LW, Pierce S (1990) Afferent and efferent innervation of the cat cochlea: quantitative analysis with light and electron microscopy. J Comp Neurol 301:443-460.

LoGiudice L, Matthews G (2009) The role of ribbons at sensory synapses. Neuroscientist 15:380-391.

Luo L, Brumm D, Ryan AF (1995) Distribution of non-NMDA glutamate receptor mRNAs in the developing rat cochlea. J Comp Neurol 361:372-382.

Matsubara A, Laake JH, Davanger S, Usami S, Ottersen OP (1996) Organization of AMPA receptor subunits at a glutamate synapse: a quantitative immunogold analysis of hair cell synapses in the rat organ of Corti. J Neurosci 16:4457-4467.

Matthews G, Sterling P (2008) Evidence that vesicles undergo compound fusion on the synaptic ribbon. J Neurosci 28:5403-5411.

Merchan-Perez A, Liberman MC (1996) Ultrastructural differences among afferent synapses on cochlear hair cells: correlations with spontaneous discharge rate. J Comp Neurol 371:208-221.

Meyer AC, Frank T, Khimich D, Hoch G, Riedel D, Chapochnikov NM, Yarin YM, Harke B, Hell SW, Egner A, Moser T (2009) Tuning of synapse number, structure and function in the cochlea. Nat Neurosci 12:444-453.

Mosbacher J, Schoepfer R, Monyer H, Burnashev N, Seeburg PH, Ruppersberg JP (1994) A molecular determinant for submillisecond desensitization in glutamate receptors. Science 266:1059-1062.

Müller M (1991a) Frequency representation in the rat cochlea. Hear Res $51: 247-254$

Müller M (1991b) Developmental changes of frequency representation in the rat cochlea. Hear Res 56:1-7.

Müller M (1996) The cochlear place-frequency map of the adult and developing Mongolian gerbil. Hear Res 94:148-156.

Neef A, Khimich D, Pirih P, Riedel D, Wolf F, Moser T (2007) Probing the mechanism of exocytosis at the hair cell ribbon synapse. J Neurosci 27:12933-12944.

Niedzielski AS, Wenthold RJ (1995) Expression of AMPA, kainate, and NMDA receptor subunits in cochlear and vestibular ganglia. J Neurosci 15:2338-2353.

Nishiki T, Augustine GJ (2004) Synaptotagmin I synchronizes transmitter release in mouse hippocampal neurons. J Neurosci 24:6127-6132.

Nouvian R, Beutner D, Parsons TD, Moser T (2006) Structure and function of the hair cell ribbon synapse. J Membr Biol 209:153-165.

Ohlemiller KK, Echteler SM (1990) Functional correlates of characteristic frequency in single cochlear nerve fibers of the Mongolian gerbil. J Comp Physiol A Neuroethol Sens Neural Behav Physiol 167:329-338.

Pan PY, Tian JH, Sheng ZH (2009) Snapin facilitates the synchronization of synaptic vesicle fusion. Neuron 61:412-424.
Parsons TD, Sterling P (2003) Synaptic ribbon. Conveyor belt or safety belt? Neuron 37:379-382.

Pickett JA, Edwardson JM (2006) Compound exocytosis: mechanisms and functional significance. Traffic 7:109-116.

Romand R (1984) Functional properties of auditory-nerve fibers during postnatal development in the kitten. Exp Brain Res 56:395-402.

Roux I, Safieddine S, Nouvian R, Grati M, Simmler MC, Bahloul A, Perfettini I, Le Gall M, Rostaing P, Hamard G, Triller A, Avan P, Moser T, Petit C (2006) Otoferlin, defective in a human deafness form, is essential for exocytosis at the auditory ribbon synapse. Cell 127:277-289.

Ruggero M (1992) Physiology and coding of sound in the auditory nerve. In: The mammalian auditory pathway: neurophysiology (Fay R, Popper, AN, eds), pp 34-93. New York: Springer.

Rutherford MA, Roberts WM (2009) Spikes and membrane potential oscillations in hair cells generate periodic afferent activity in the frog sacculus. J Neurosci 29:10025-10037.

Safieddine S, Wenthold RJ (1999) SNARE complex at the ribbon synapses of cochlear hair cells: analysis of synaptic vesicle- and synaptic membraneassociated proteins. Eur J Neurosci 11:803-812.

Siegel JH (1992) Spontaneous synaptic potentials from afferent terminals in the guinea pig cochlea. Hear Res 59:85-92.

Singer JH, Diamond JS (2006) Vesicle depletion and synaptic depression at a mammalian ribbon synapse. J Neurophysiol 95:3191-3198.

Singer JH, Lassová L, Vardi N, Diamond JS (2004) Coordinated multivesicular release at a mammalian ribbon synapse. Nat Neurosci 7:826-833.

Sun J, Pang ZP, Qin D, Fahim AT, Adachi R, Südhof TC (2007) A dual$\mathrm{Ca} 2+$-sensor model for neurotransmitter release in a central synapse. Nature 450:676-682.

Suryanarayanan A, Slaughter MM (2006) Synaptic transmission mediated by internal calcium stores in rod photoreceptors. J Neurosci 26:1759-1766.

Taberner AM, Liberman MC (2005) Response properties of single auditory nerve fibers in the mouse. J Neurophysiol 93:557-569.

Takahashi T (2005) Postsynaptic receptor mechanisms underlying developmental speeding of synaptic transmission. Neurosci Res 53:229-240.

Taschenberger H, von Gersdorff H (2000) Fine-tuning an auditory synapse for speed and fidelity: developmental changes in presynaptic waveform, EPSC kinetics, and synaptic plasticity. J Neurosci 20:9162-9173.

Taschenberger H, Leão RM, Rowland KC, Spirou GA, von Gersdorff H (2002) Optimizing synaptic architecture and efficiency for high-frequency transmission. Neuron 36:1127-1143.

Vardjan N, Jorgacevski J, Stenovec M, Kreft M, Zorec R (2009) Compound exocytosis in pituitary cells. Ann N Y Acad Sci 1152:63-75.

Wall MJ, Usowicz MM (1998) Development of the quantal properties of evoked and spontaneous synaptic currents at a brain synapse. Nat Neurosci 1:675-682.

Wall MJ, Robert A, Howe JR, Usowicz MM (2002) The speeding of EPSC kinetics during maturation of a central synapse. Eur J Neurosci 15:785-797.

Walsh EJ, McGee J (1987) Postnatal development of auditory nerve and cochlear nucleus neuronal responses in kittens. Hear Res 28:97-116.

Yamashita T, Ishikawa T, Takahashi T (2003) Developmental increase in vesicular glutamate content does not cause saturation of AMPA receptors at the calyx of held synapse. J Neurosci 23:3633-3638.

Zampini V, Johnson SL, Franz C, Lawrence ND, Muenkner S, Engel J, Knipper M, Magistretti J, Masetto S, Marcotti W (2010) Elementary properties of CaV1.3 Ca2+ channels expressed in mouse cochlear inner hair cells. J Physiol 588:187-199.

Zenisek D (2008) Vesicle association and exocytosis at ribbon and extraribbon sites in retinal bipolar cell presynaptic terminals. Proc Natl Acad Sci U S A 105:4922-4927. 